\title{
Development and Characterization of Fe-Based Friction Material Made by Hot Powder Preform Forging for Low Duty Applications
}

\author{
A.A.S. Ghazi*, K. Chandra, P.S. Misra \\ Department of Metallurgical and Materials Engineering, Indian Institute of Technology \\ Roorkee, India. \\ *Corresponding Author: aas_ghazi@yahoo.com
}

\begin{abstract}
:
This present paper investigates the friction and wear properties of friction material developed by 'Hot Powder Preform Forging' technique. The conventional technique to manufacture Metallo-ceramic brake pads was successfully and economically tried to replace the above process. Compacting and sintering technology suffers from certain major limitations such as inadequate joining of friction element with backing plate, poor density levels achieved in friction element owing to limited application of pressure during compacting, poor thermal conductivity due to high levels of porosity in the product, poor strength due to segregation of the impurities along prior particle boundaries (PPB's) and, wide variations in final characteristics due to large number of variables involved. In contrast to these limitations, the present technique can offer brake pads of much simpler chemistry but with improved performance on account of simultaneous application of pressure and temperature and with better control of variables. Fade and recovery studies were carried out on a Krauss machine tester following the Economic Commission for Europe Regulation for

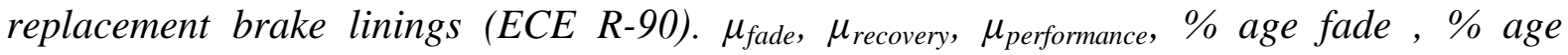
recovery \& temperature rise lie within the range for friction materials used for low duty applications. The mechanical properties of these materials were characterized using ASTM standards.
\end{abstract}

Keywords: Friction material; Preform forging; Brake pads; Fade.

\section{INTRODUCTION}

Brakes are one of the most important safety and performance components in automobiles. Most of the brake linings used in American cars are based on a metal fiber reinforced phenolic resin matrix and are called semi metallic. There are, however, also other types of lining materials, categorized into metallic, organic and carbon based. Most of the brake linings are typically a composite of a number of different materials. Sometimes, up to 20 or 25 different constituents are used. These ingredients are categorized into four broad classes: binders, structural materials, fillers and frictional additives/modifiers. The binders bind together rest of the ingredients, structural materials provide the structural reinforcement to the 
composite matrix, fillers make up the volume of the brake lining, while keeping the costs down, and friction modifiers stabilize the coefficient of friction [1].

A limited number of studies investigating the compositional effect are available in the literature and a complete analysis concerning all the ingredients in a friction material is seldom found. The limited information about ingredients used in the friction material and their effects on the friction characteristics is partly ascribed to proprietary reasons [2-6]. The development of new pad materials is a complicated matter as the components interact and synergetic effects that are hard to disentangle arise [7].

Compacting and sintering technology [8] is one such technology through which Metalloceramic brake pads are currently being made. However, it suffers from certain major limitations such as inadequate joining of friction element with backing plate, poor density levels achieved in friction element owing to limited application of pressure during compacting, poor thermal conductivity due to high levels of porosity in the product, poor strength due to segregation of the impurities along prior particle boundaries (PPB's), anisotropy in the strength of the product owing to preferred direction due of pressing, and, wide variations in final characteristics due to large number of variables involved. Besides above, cost of raw material and consumables along with heavy capital equipment makes this technique costly and only large scale production is possible where these costs are distributed in the large volume of production. In contrast to these limitations, the present technique can offer brake pads of much simpler chemistry but with improved performance on account of simultaneous application of pressure and temperature and with better control of variables. The technique does not involve any custom built equipment and is also likely to become economical even with small volume production [9].

\section{EXPERIMENTAL}

Friction materials investigated in this study are iron-based metal matrix composites which are produced by 'Hot Powder Preform Forging' technique. The compositions are given in Table 1. Samples of the dimension $(25 \mathrm{~mm} \times 50 \mathrm{~mm} \times 10 \mathrm{~mm})$ for testing on Krauss Machine Tester are prepared as follows which is used to check the suitability of friction materials to be used for low and moderate duty applications. The particle size of the raw materials chosen in the present investigation is given in Table 2. Powder mixtures for friction layer as per the chemistry are prepared. Firstly, SiC powder is mechanically alloyed with sulphide / sulphate powders, graphite powder (fine $-1 / 3$ rd of the total \% age), etc. This will ensure coating of soft powders on hard SiC powder. The attritor speed ranges from $150 \mathrm{rpm}$ to $200 \mathrm{rpm}$, ball to charge ratio is 5:1 and the duration is 2 hrs (Powder Mix-1). Then, entire amount of iron and other powders such as $\mathrm{Cu}, \mathrm{Zn}$, etc as per the chosen chemistry is mechanically alloyed with graphite powder (flake $-2 / 3$ rd of the total $\%$ age) in the attritor with the same operating parameters (Powder Mix-2). Lastly, the two powder mixtures (Powder Mix-1 and Powder Mix-2) are then mechanically mixed with each other in a ball mill (180 rpm) for 2 hrs.

Powder compaction is done in a suitably designed die in accordance with the given shape of the Krauss Machine Tester sample by pressing in a Screw forging press with the help of upper and lower punches at a pressure of $750 \mathrm{MPa}$. The compacts are then ejected out of the die. The die is suitably lubricated employing graphite in the suspension of methyl alcohol/ethyl alcohol/acetone for easy ejection without cracking of green compact. Green compacts are then coated with high temperature resistant ceramic glassy coating [10] and are dried completely. The purpose of this coating is to protect samples from oxidation at high 
temperature. The green compacts so produced are heated in a furnace. The operating temperature of the furnace ranges from $1050^{\circ} \mathrm{C} 1100^{\circ} \mathrm{C}$ for iron based brake pad and the holding time is $1 / 2$ hours.

Table 1: Chemistry of friction materials, density and hardness

\begin{tabular}{|c|c|c|c|c|c|c|c|c|c|c|c|c|}
\hline \multirow{2}{*}{$\begin{array}{l}\text { Identific } \\
\text { ation no. }\end{array}$} & \multirow{2}{*}{$\begin{array}{l}\mathrm{Cu} \\
\%\end{array}$} & \multirow{2}{*}{$\begin{array}{c}\text { Graphite } \\
\%\end{array}$} & \multirow{2}{*}{$\begin{array}{l}\mathrm{P} \\
\%\end{array}$} & \multirow{2}{*}{$\begin{array}{l}\text { Sn } \\
\%\end{array}$} & \multirow{2}{*}{$\begin{array}{l}\mathrm{SiC} \\
\%\end{array}$} & \multirow{2}{*}{$\begin{array}{c}\mathrm{Sb}_{2} \mathrm{~S} \\
{ }_{3} \%\end{array}$} & \multirow{2}{*}{$\begin{array}{c}\mathrm{BaSO}_{4} \\
\%\end{array}$} & \multirow{2}{*}{$\begin{array}{l}\mathrm{Zn} \\
\%\end{array}$} & \multirow{2}{*}{$\begin{array}{c}\mathrm{CaSO}_{4} \\
\%\end{array}$} & \multirow{2}{*}{$\begin{array}{l}\mathrm{Fe} \\
\%\end{array}$} & \multicolumn{2}{|c|}{ Forged Samples } \\
\hline & & & & & & & & & & & $\begin{array}{l}\text { Density } \\
(\mathrm{gm} / \mathrm{cc})\end{array}$ & $\begin{array}{l}\text { Hardness } \\
(\mathrm{BHN})\end{array}$ \\
\hline FM-1 & 10 & 6 & 0.8 & 3 & --- & --- & --. & --. & 1 & Balance & 5.2 & 110 \\
\hline FM-2 & 10 & 8 & 0.4 & 2 & 3.5 & 1 & 6 & -- & --- & Balance & 6.06 & 95 \\
\hline FM-3 & 10 & 8 & 0.8 & 1 & 3.5 & 1 & 6 & -- & $\cdots--$ & Balance & 5.9 & 116 \\
\hline FM-4 & 11 & 9 & 0.3 & $\cdots$ & 5 & 2.5 & 5 & 1 & -.-- & Balance & 6.1 & 115 \\
\hline $\begin{array}{l}\text { Resin } \\
\text { Bonded } \\
\text { Friction } \\
\text { Material }\end{array}$ & -- & --- & $\cdots$ & -- & --. & --- & --- & -- & --- & --- & 2.579 & 180 \\
\hline
\end{tabular}

Table 2: Particle size of powders employed

\begin{tabular}{lll}
\hline S. No. & Powder & Size range $(\mu \mathrm{m})$ \\
\hline 1 & Iron powder & -120 \\
2 & Copper/Zinc powder & -120 \\
3 & Graphite & -200 to +150 \\
4 & Ferro-phosphorus & -45 \\
5 & Tin powder & -75 \\
6 & Silicon Carbide & -180 to +150 \\
7 & Calcium Sulphate/ Barium Sulphate/ & -45 \\
& Antimony Trisulpide & \\
\hline
\end{tabular}

The hot powder preforms are then taken out from the furnace and quickly transferred into the hot lubricated die fitted in the forging press (capacity of press depending upon area of the actual brake pad) and having speed $50-500 \mathrm{~mm} / \mathrm{s}$. The preform is fully consolidates to its near theoretical density on forging. The forged component is thereafter ejected out of the die. Forged samples are again coated with glassy coating, and then they are annealed at a temperature of $710^{\circ} \mathrm{C}$ for 2 hours durations. The process flow sheet is given in Fig. 1.

\section{RESULTS AND DISCUSSION}

\subsection{Determination of Density:}

The basic method of determining the density of Krauss Machine Tester sample is by measuring the ratio of mass and volume of the specimen was used. Density depends upon extent of forging and normalizing/annealing treatments thereafter. It also indirectly depends upon chemistry of friction materials. In this paper, the densities of Krauss Machine Tester samples are estimated by Archimedes principle as shown in Table 1. The density of Sintered Fe-based samples are higher than resin bonded friction material which results in better properties of sintered material. 


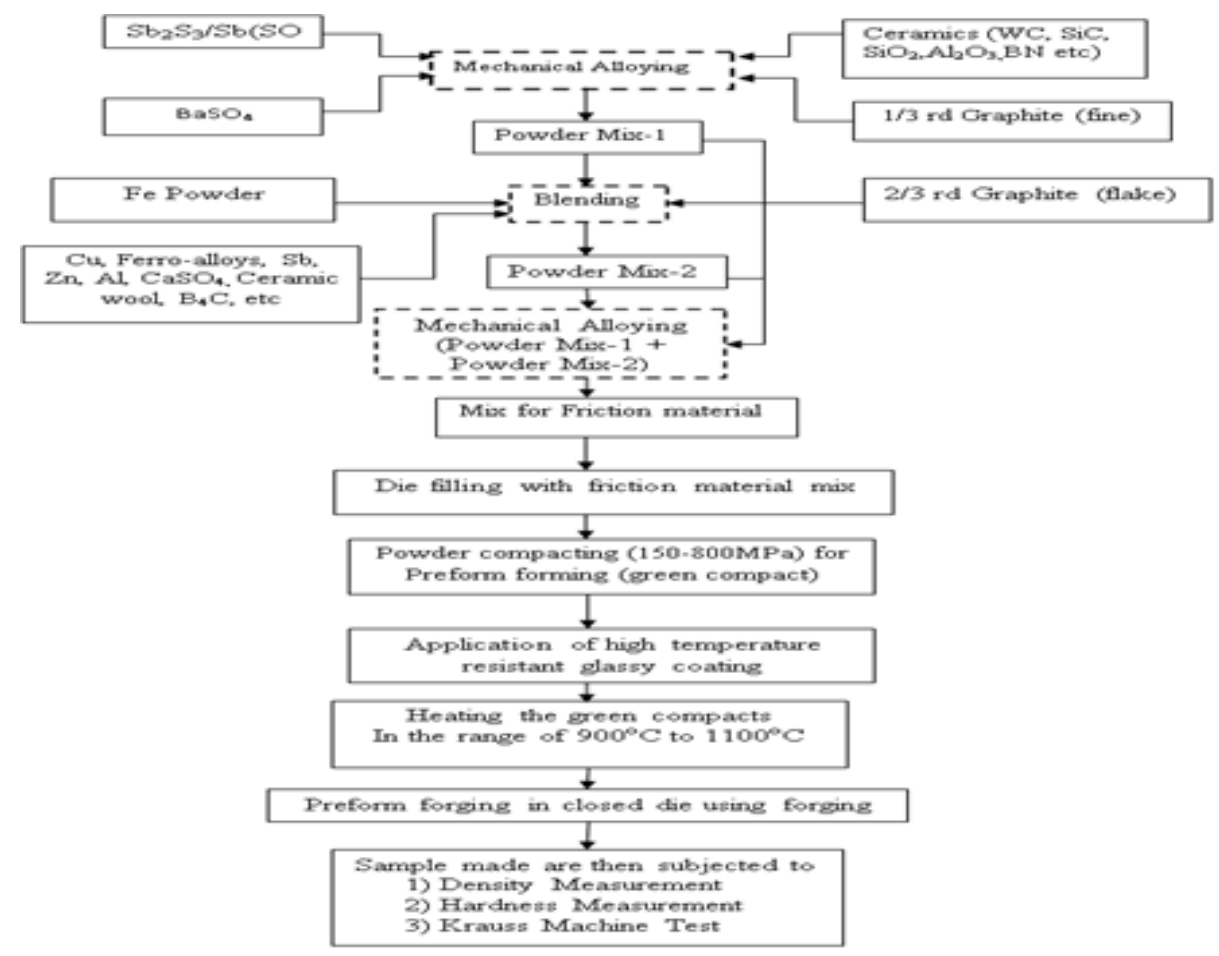

Fig. 1: Process Flow Sheet

\subsection{Brinell Hardness Test:}

The Brinell hardness test method consists of indenting the test material with a $10 \mathrm{~mm}$ diameter hardened steel ball subjected to a load of $31.25 \mathrm{~kg}$ applied for 10-15 s. The diameter of the indentation left in the test material is measured with a low powered microscope. The diameter of the impression is the average of two readings at right angles and the use of a Brinell hardness number table can simplify the determination of the Brinell hardness. The hardness values obtained for the organic-based material and Fe-based materials were of 180 HB and 95-120 HB, respectively. The sintered materials hardness was too small, most likely due to its high porosity as well as the small hardness of the base metal. This result might have affected the sintered pad in a way that it suffered similar wear to the resin-based pad, no matter what was the metallic base of the material. Despite the very different hardness presented by each material, the sintered Fe- based friction material proved to have a superior resistance to compression when compared to the resin-based material. Brinell hardness number of test pins is shown in Table 1.

\subsection{Fade and Recovery Evaluation:}

The fade and recovery tests were conducted on the six compositions using a Krauss type RWDC 100C (450 V/50 Hz) machine shown schematically in Fig. 2. The input parameters are given in Table 3. Wear volume of the composites was calculated using weight change and the density of the materials. On the basis of the results showed in Table 4, it can be inferred that sintered Fe- based friction materials have better properties than resin bonded friction materials. From Fig. 3(d), it was observed that FM-03 composite have exhibited lowest Performance $\mu$ and FM-04 shows the highest one. The performance $\mu$ order was Resin bonded friction material $(\mathrm{RBFM})>$ FM-04 $>$ FM-01 $>$ FM-02 $>$ FM-03, while $\mu$ after recovery [Fig. 3 (e)] of the composites was in order FM-04 $>$ RBFM $>$ FM-02 $>$ FM-01 $>$ 
FM-03. The fade $\mu$ [Fig. 3(c)] order is RBFM $>$ FM-01 $>$ FM-04 $>$ FM-02 $>$ FM-03 and it shows that fade $\mu$ is lowest for FM-03. The \% age fade [Fig. 3 (a)] is lowest for FM-01 and follows the order FM-04 $>$ FM-02 $>$ RBFM $>$ FM-03 $>$ FM-01. The $\%$ age recovery [Fig. 3(b)] is maximum for FM-02 and follows the order FM-02 $>$ FM-04 $>$ FM-01 $>$ FM-03 $>$ RBFM. The temperature order is as follows RBFM $>$ FM-04 $>$ FM-02 $>$ FM-01 $>$ FM-03 [Fig. 3(f)]. The fade and recovery characteristics of all the four composites studied have been observed to be well within the IS 2742 prescribed permissible ranges of $0-30$ and $90-140 \%$, respectively. Therefore, sintered Fe- based friction materials are superior to resin bonded friction materials.

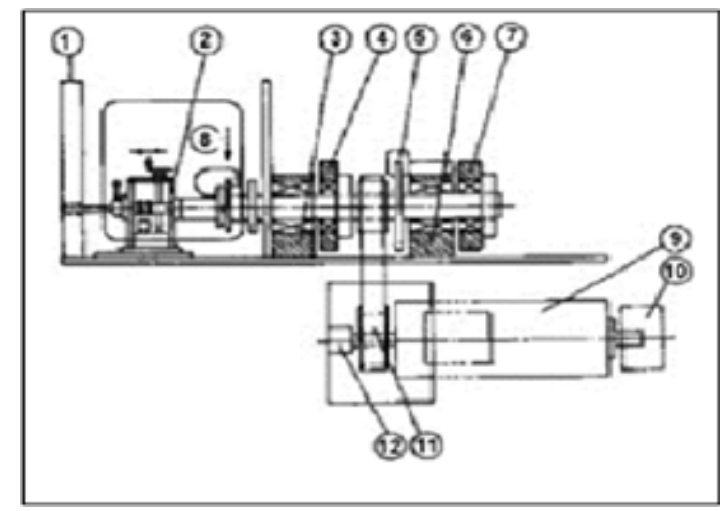

Fig. 2 : Schematic of Krauss Machine: (1) compressed air supply, (2) bearings movable, (3) bearings, (4) option SH $2.5 \mathrm{~kg} \mathrm{~m} \mathrm{~m}$, (5) emergency stop option, (6) bearings,(7) options SH $5 \mathrm{~kg} \mathrm{~m}^{2}$, (8) air inlet, (9) d. c. motor, (10) clutch at option SH, (11) belt drive and (12) generator.

Table 3: Input parameters for Krauss Test

\begin{tabular}{ll}
\hline Parameters & Value \\
\hline Pressure & $10 \mathrm{bar}$ \\
Moment of Inertia & $2.5 \mathrm{~kg} \mathrm{~m}^{2}$ \\
Area of sample & $25 \times 50 \mathrm{~mm}^{2}$ \\
Mean contact radius & $101 \mathrm{~mm}$ \\
Rpm & 660 \\
\hline
\end{tabular}

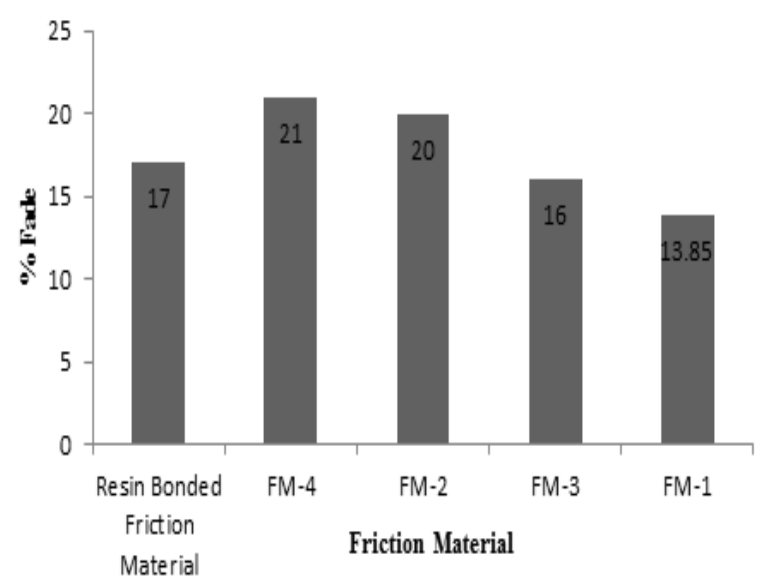

Table 4: Results for Fe-based and Resin Bonded Friction Materials (Krauss Machine Test)

\begin{tabular}{ccc}
\hline Properties & $\begin{array}{c}\text { Iron based } \\
\text { Friction } \\
\text { Materials }\end{array}$ & $\begin{array}{c}\text { Resin bonded } \\
\text { Friction } \\
\text { Materials }\end{array}$ \\
\hline$\mu_{\text {performance }}$ & $0.314-0.342$ & $0.390-0.429$ \\
$\mu_{\text {recovery }}$ & $0.351-0.434$ & $0.426-0.454$ \\
$\mu_{\text {fade }}$ & $0.260-0.311$ & $0.328-0.386$ \\
\hline
\end{tabular}

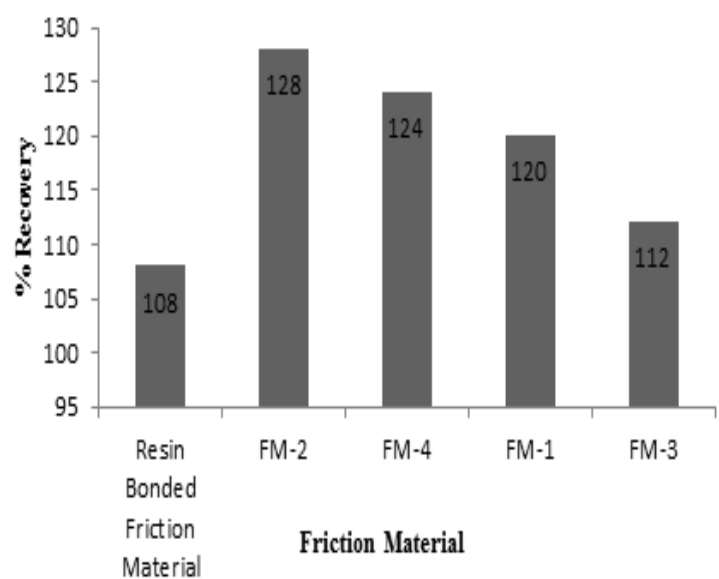

Fig. 3(a): \% age Fade Vs Friction Materials Fig. 3(b): \% age Recovery Vs Friction Materials 

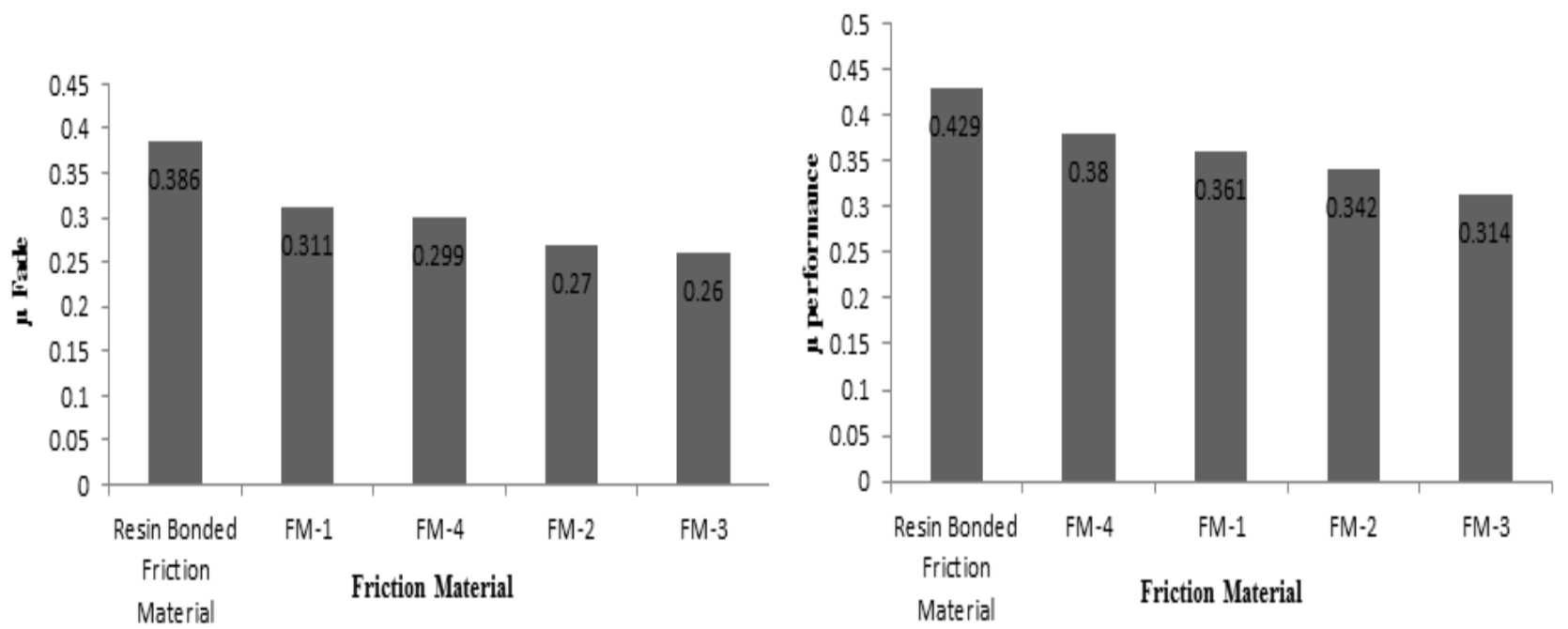

Fig. 3(c): $\mu_{\text {fade }}$ Vs Friction Materials

Fig. 3(d): $\mu_{\text {performance }}$ Vs Friction Materials
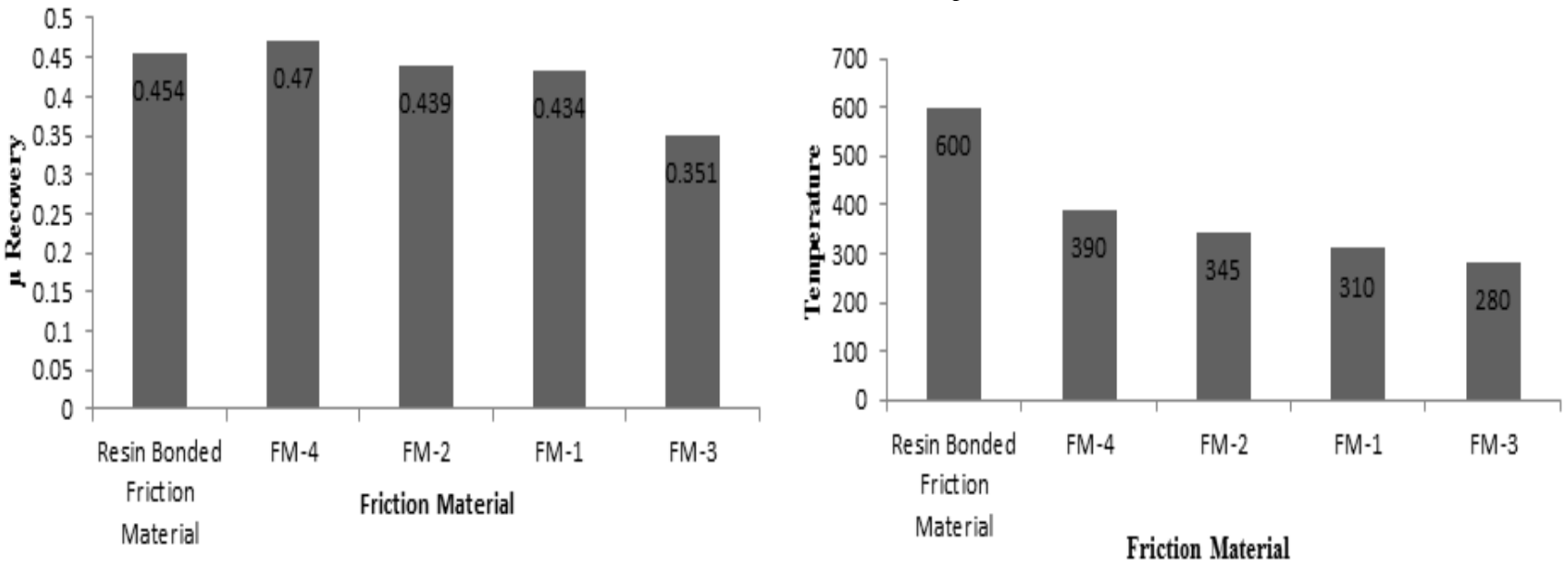

Fig. 3(e): $\mu_{\text {recovery Vs Friction Materials }}$ Materials

Fig. 3(f): Temperature Rise Vs Friction

\subsection{SEM/EDAX:}

In order to get the detailed information about different constituents, EDAX analysis was also performed including their micro-analysis. Fig. 4 (a), (b) \& (c) shows the SEM/EDAX of the friction material FM-01, FM-02 and FM-03 resp..
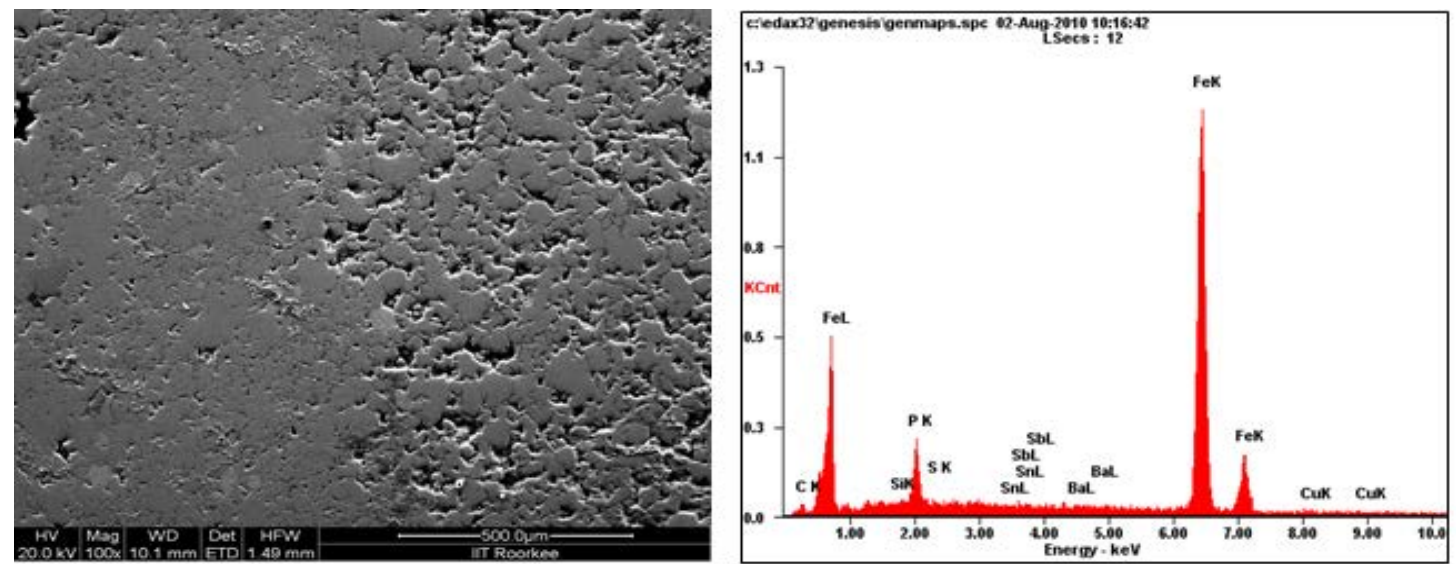

Fig. 4(a): SEM/EDX of FM-01 

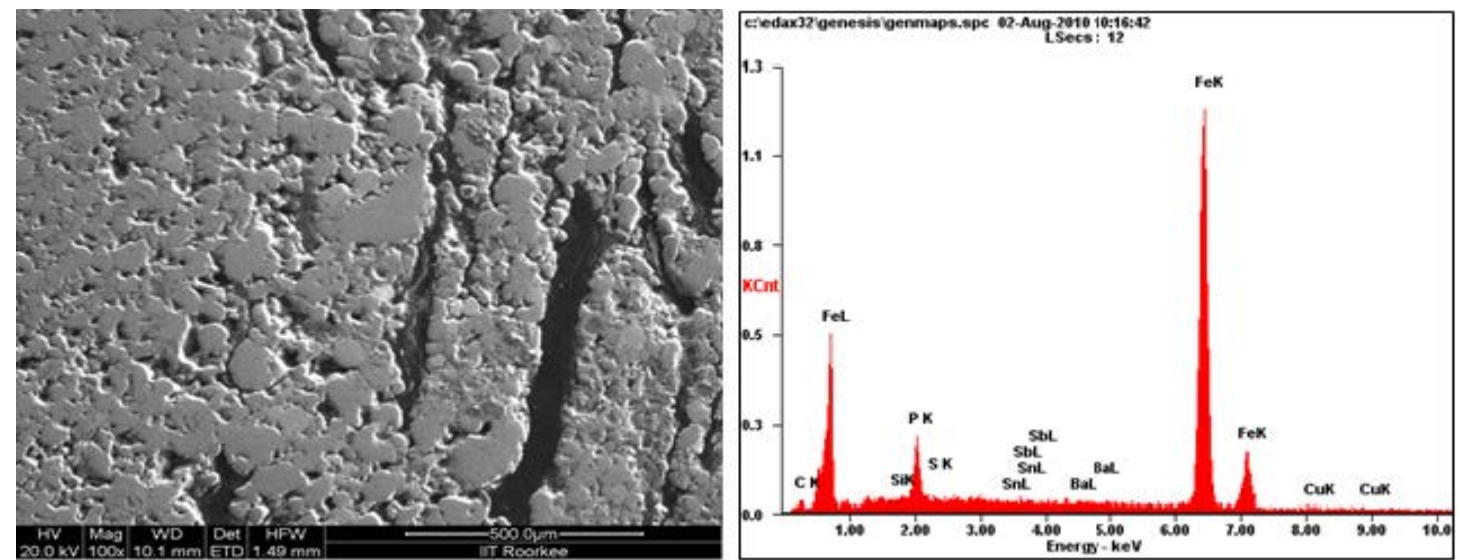

Fig. 4(b): SEM/EDX of FM-02

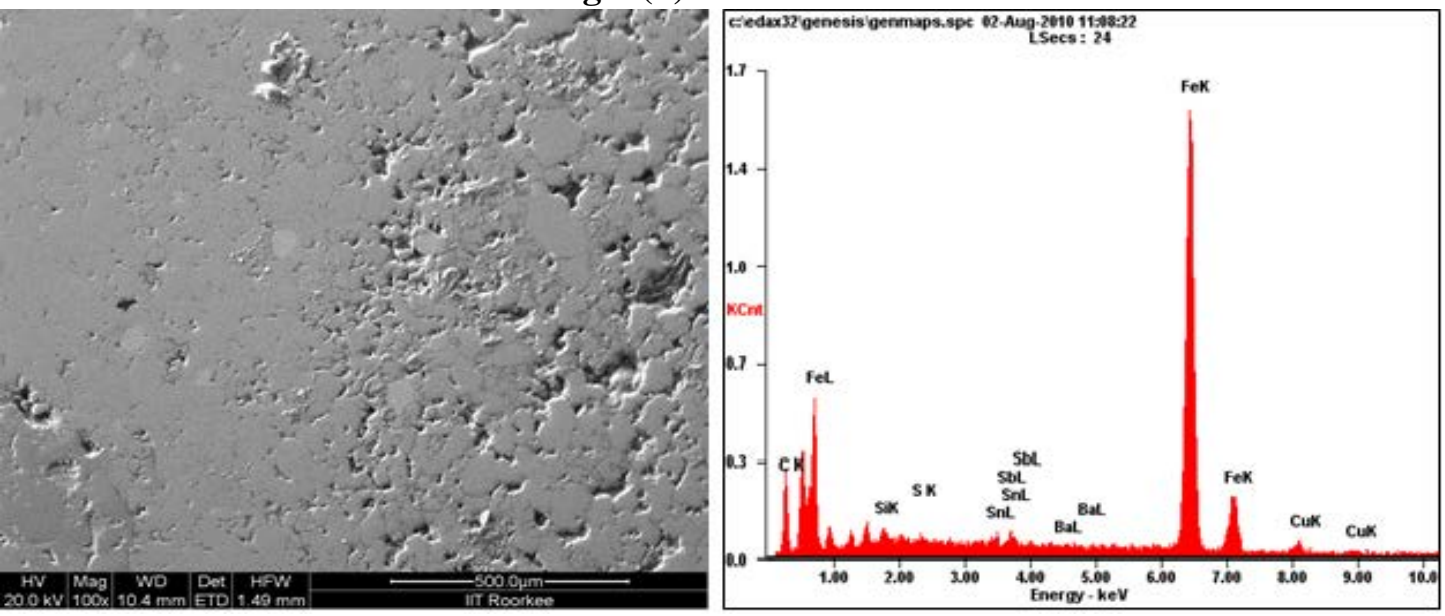

Fig. 4(c): SEM/EDX of FM-03

\section{CONCLUSIONS}

Based on the results obtained, the sintered Fe- based friction materials proved to be more efficient than the resin-based friction materials because it presents a relatively lower wear rate as well as a higher friction coefficient. The wear rate in the sintered material was lower due to the good ductility of its metallic matrix. Due to the presence of SiC, it was possible to obtain an increase of the friction coefficient in the sintered material. To improve the thermal conductivity of the material, it is important to decrease the matrix porosity, so that it is possible to improve the brake pad efficiency. As previously mentioned, studies about friction materials are based on trial and error testing procedures. It is through changes in the base materials, in the manufacturing processes and even in the work conditions that really different results can be noticed. The present study suggests that each friction material needs a specific focus of study. Iron based brake pads can be used for low duty applications. The technology completely eliminates the problems of joining between backing plate and friction element on account of simultaneous application of pressure and temperature. The porosity of the material may cause higher temperature increase when the system operates because the pores work as insulators in the material, and they make the heat transference difficult. In one instance, this increasing in porosity presented some benefits related to the application of the friction material, since it increases the material roughness, promoting an increase in the friction with the brake disc. Another benefit brought about by porosity was to keep the abrasive particles in the material, avoiding their loss during braking action. 


\section{REFERENCES}

1. M. Eriksson, "Friction and contact phenomena of disc brakes related to squeal", Comprehensive summaries of Uppsala dissertations from the Faculty of Science and Technology 537, ACTA Universitatis Upsaliensis, 2000.

2. S. J. Kim, M. H. Cho, D. S. Lim, H. Jang, Wear 251, 2001, pp. 1484-1491.

3. S. J. Kim, H. Jang, Tribol. Int. 33, 2000, pp. 477-484.

4. A. P. Verma, B. Vishwanath, C. V. S. Kameswara Rao, Wear 193, 1996, pp.193-198.

5. H. Jang, S. J. Kim, Wear 239, 2000, pp. 229-236.

6. T. Kato, A. Magario, Tribol. Trans. 37, 1994, pp. 559-565.

7. Luise Gudmand-Høyer , Allan Bach , Georg T. Nielsen , Per Morgen, Wear 232, 1999, pp. 168- 75 .

8. R. H. T. Dixon, Clayton A., "Powder Metallurgy for engineers”, Machinery Publishing Co. Ltd., London, 1971, pp. 166-183.

9. D. Dutta, G. Mohan, B. Chatterjee, C. G. Krishnadas Nair, "Development of sintered metalloceramic friction material for the wheel brakes of a military transport aircraft", published in, 'Composites: Science and Technology (ISBN 81-224-1251-3)', edited by R.C. Prasad, P. Ramakrishan, New Age International (P) Ltd., New Delhi, 2002, pp. 94114.

10. P. S. Misra, K. Chandra, "Development of High Temperature Oxidation Resistant Glassy Coating”, Indian Patent, Application no. 153/DEL/2010 dated Jan. 27, 2010. 